\title{
REDES SOCIAIS, JORNALISMO E ELEIÇÕES LOCAIS EM 2016: O FACEBOOK COMO ESPAÇO DE VISIBILIDADE DA POLÍTICA E DOS POLÍTICOS NOS JORNAIS O ESTADO DO MARANHÃO (MA) E A TARDE (BA) 123
}

\author{
Regilson Furtado Borges 4
}

\section{RESUMO}

Este artigo apresenta os resultados parciais de um projeto de pesquisa desenvolvido no Grupo de Pesquisa em Comunicação, Política e Sociedade (COPS), da UFMA. O objetivo aqui é analisar como as eleições (e, mais especificamente, os candidatos a prefeito) aparecem e ganham visibilidade na cobertura jornalística feita pelos jornais O Estado do Maranhão (MA) e A Tarde (BA), nas suas páginas do Facebook. Trata-se de um estudo comparado da cobertura jornalística de jornais de diferentes localidades do Nordeste — sendo um deles um dos maiores jornais do Nordeste e, o outro, um dos menores - para compreender qual espaço é destinado por eles ao tema político-eleitoral, além de identificar qual o tratamento que os candidatos recebem em cada veículo, a partir do conteúdo que circula e ganha destaque na rede social. A técnica de pesquisa aqui empregada é a de análise de conteúdo, a partir de uma abordagem quantitativa. O período da coleta dos dados compreende toda a disputa eleitoral de 2016, com início em 16 de agosto e término em 2 de outubro, de quando foram extraídas 1.871 postagens do Facebook dos dois veículos, por meio do aplicativo Netvizz. Analisa-se o tema das postagens, a abordagem específica sobre as eleições, a presença dos candidatos e o modo como aparecem. Conclui-se que os veículos possuem agendas distintas: enquanto o jornal A Tarde prioriza temas considerados soft, o jornal $\mathrm{O}$ Estado do Maranhão evidencia as hard news. Além disso, os dois periódicos deram atenção ao tema políticoeleitoral quando a disputa eleitoral estava próxima do fim.
\end{abstract}

Palavras-chave: Jornalismo. Eleições 2016. Campanha eleitoral.

\begin{abstract}
This article aims to analyse how the elections and, more specifically, the candidates appear and gain visibility in the journalistic coverage made by the newspapers O Estado de Maranhão (MA) and A Tarde (BA), in their Facebook pages. This is a comparative study of journalistic coverage of newspapers from different locations in the Northeast - one of them being a big newspaper and the other a small one - in order to understand the space allocated to the political-electoral issue. In addition, the article identifies how the candidates were approached in each newspaper, from the content that circulates and gains prominence in the social network. The methodology employed is the content analysis, based on a quantitative approach. The period of analysis comprises the 2016 electoral contest, which began on August 16 and ended on October 2, in which 1.871 posts were extracted from the two vehicles using the application Netvizz. The article analyses the issues, the specific approach to elections and the presence of candidates on the posts. The research concludes that the newspapers have different agendas: while the newspaper A Tarde prioritizes topics considered soft, the newspaper O Estado do Maranhão presents more hard news. In addition, the two newspapers paid attention to the political-electoral issue in the period closest to the day of the election.
\end{abstract}

Keywords: Journalism. Elections 2016. Election Campaign.

\section{RESUMEN}

Este artículo tiene el objetivo de analizar cómo las elecciones (y, más específicamente, los candidatos a alcalde) aparecen y ganan visibilidad en la cobertura periodística hecha por los periódicos O Estado do Maranhão (MA) y A Tarde (BA), en las páginas de Facebook. Se trata de un estudio comparado de la cobertura periodística de

\footnotetext{
${ }^{1}$ Este artigo apresenta alguns resultados da pesquisa "Cobertura jornalística em período eleitoral e a circulação de informação em redes sociais: um estudo das fanpages dos principais jornais da região Nordeste", financiada pela Fundação de Amparo à Pesquisa e Desenvolvimento do Estado do Maranhão (Fapema), edital Universal de 2016.

${ }^{2}$ DOI: http://dx.doi.org/10.5380/recp.v8i2.56300

${ }^{3}$ Submetido em: 30 de setembro de 2017. Aprovado em: 15 de outubro de 2017.

${ }^{4}$ Graduado em Comunicação Social - Jornalismo pela Universidade Federal do Maranhão (UFMA), campus de Imperatriz. Membro do Grupo de Pesquisa em Comunicação, Política e Sociedade (COPS) e, durante a execução da pesquisa, foi pesquisador voluntário do Programa Institucional de Bolsas de Iniciação Científica (PIBIC). Email: regilsonfurtado@gmail.com.
} 
periódicos de diferentes localidades de la región Nordeste - siendo uno de ellos uno de los mayores periódicos del Nordeste y, el otro, uno de los menores - para comprender cuál es el espacio ofrecido al tema políticoelectoral. Además, se identifica cuál es el tratamiento que los candidatos reciben en cada periódico, a partir del contenido que circula y gana destaque en la red social. La técnica de investigación empleada es el análisis del contenido, a partir de un abordaje cuantitativo. El período de recolección de datos comprende toda la disputa electoral de 2016, que comienza en el 16 de agosto y termina en el 2 de octubre, en la que se extrajeron 1.871 posts de los dos vehículos a través de Netvizz. En el artículo se analiza el tema, el enfoque específico sobre las elecciones, la presencia de los candidatos y el modo como aparecen. La investigación concluye que los vehículos poseen agendas distintas: mientras que el diario A Tarde prioriza temas considerados soft, el diario O Estado de Maranhão presenta más hard news. Además, los dos periódicos destinan más atención al tema político-electoral en el período más próximo al día de la elección.

Palabras clave: Periodismo. Elecciones 2016. Campaña electoral.

\section{INTRODUÇÃO}

As eleições contam, atualmente, com um novo espaço para a veiculação das informações dos candidatos que disputam os pleitos eleitorais. As redes sociais estão se configurando como plataformas não só de entretenimento para os usuários, e passaram a ser vistas, pelos meios de comunicação, como uma ferramenta capaz de potencializar notícias a respeito das campanhas eleitorais (TAVARES; MASSUCHIN, 2015), tema relevante no momento da disputa. A internet, nas campanhas, pode ser usada tanto pelos próprios partidos e candidatos, para ofertarem conteúdo de caráter próprio, quanto pelos meios de comunicação, que possuem, agora, um espaço adicional para distribuir conteúdo de interesse público (especificamente, sobre as campanhas eleitorais).

Este $\operatorname{artigo}^{5}$ trata, mais especificamente, do Facebook como espaço de visibilidade para o tema político-eleitoral e dos candidatos a prefeito nas eleições municipais de 2016. A pesquisa empírica analisa os jornais O Estado do Maranhão (MA) e A Tarde (BA), durante o primeiro turno do período eleitoral - sendo um deles um dos maiores jornais do Nordeste e, o outro, um dos menores. Para esta escolha levou-se em consideração a circulação impressa de cada um deles. Este trabalho compara os dois jornais por meio do método quantitativo de análise de conteúdo, bem como eles fizeram a cobertura jornalística dos temas relacionados às eleições de 2016, além de identificar como concedem espaço aos candidatos. Os jornais analisados são, também, os mais tradicionais de cada estado.

As análises referentes à cobertura eleitoral (SILVA; PELLIZZARO, 2015) permitem criar uma dimensão de como a mídia tem dado espaço aos temas de interesse público, além de nos permitir observar como a imprensa distribui as notícias pelo Facebook (TAVARES;

\footnotetext{
${ }^{5}$ Este artigo apresenta resultados do trabalho de conclusão de curso que tem como título Política, redes sociais e jornalismo: um estudo comparativo das fanpages dos jornais "A Tarde" (BA) e "O Estado do Maranhão" (MA), defendido em agosto de 2017 e que foi orientado pela Prof. Dr. Michele Goulart Massuchin, docente do curso de Comunicação Social - Jornalismo da UFMA e coordenadora do COPS.
} 
BORGES, R. F. Redes sociais, jornalismo e eleições locais em 2016: o Facebook como espaço de visibilidade da política e dos políticos nos jornais $O$ Estado do Maranhão (MA) e A Tarde (BA)

MASSUCHIN, 2015) e de que forma os candidatos ao cargo do executivo são tratados pelos jornais aqui analisados.

Os meios de comunicação ocupam um lugar central no período eleitoral. Este é o momento onde as atenções da sociedade se voltam para as principais questões que giram em torno dos candidatos e de suas respectivas campanhas. $\mathrm{O}$ acompanhamento da produção jornalística neste período, no ambiente online, possibilita conferir quais são os temas priorizados na agenda da mídia e o que é dito a respeito aos candidatos. Por isso, diversas pesquisas (TAVARES; MASSUCHIN, 2015; MASSUCHIN; CARVALHO, 2016) têm contribuído para fomentar as discussões acerca da visibilidade que os candidatos e os temas relativos às campanhas eleitorais vêm ganhando não só na imprensa tradicional (jornais impressos, rádio e TV), mas também nas redes sociais digitais.

As análises sobre cobertura jornalística no período eleitoral permitem entender o que ganha destaque ou não no noticiário político (JAKOBSEN, 2007). Além do mais, fazer a comparação de jornais em grandes períodos colabora para identificar como a mídia trata determinados temas, além de observar quais as diferenças e semelhanças na cobertura dos veículos em questão. O período eleitoral é, também, uma época em que o posicionamento político dos veículos de comunicação fica em evidência, podendo ser identificado (JAKOBSEN, 2007).

Os dados dos dois jornais correspondem ao primeiro turno das eleições de 2016, que vai de 16 de agosto até o dia 2 de outubro. A análise foi realizada com base em um livro de codificação, com as variáveis e categorias utilizadas. Os dados coletados correspondem a $1.871^{6}$ postagens realizadas pelos jornais naquele período, que foram extraídas do Facebook pelo aplicativo Netvizz.

Este trabalho, ainda, está divido em três tópicos de caráter teórico, que trazem discussões sobre o papel da opinião pública nos meios de comunicação, a relação entre o jornalismo o interesse público e a maneira como o jornalismo passou a circular informações no ambiente digital, dando destaque aos temas de interesse público, com ênfase nas campanhas eleitorais. As demais partes se dividem entre a apresentação da abordagem metodológica, a discussão dos resultados empíricos sobre como os temas políticos ganham visibilidade na página dos jornais e, por fim, as conclusões do trabalho.

\footnotetext{
${ }^{6}$ Este trabalho apresenta parte da pesquisa "Cobertura jornalística em período eleitoral e a circulação de informação em redes sociais: um estudo das fanpages dos principais jornais da Região Nordeste", realizada em 2016 pelos alunos do COPS.
} 


\section{OPINIÃO PÚBLICA E O PAPEL DOS MEIOS DE COMUNICAÇÃO}

O jornalismo precisa de credibilidade para funcionar como atividade profissional. Segundo Gomes e Cabral (2011), o jornalismo conquista a sua confiança como um prestador de serviço público quando consegue passar informações de forma correta e o mais isenta possível para a sociedade. Sobre a relação do jornalismo com a opinião pública, Gomes e Cabral (2011) discutem que o repasse de informações corretas para a população contribui para que esta possa formar sua opinião acerca de vários assuntos, o que torna-se importante, principalmente, em períodos eleitorais, onde os cidadãos precisam decidir seu voto.

No dia a dia as pessoas recorrem aos meios de comunicação para buscar as informações mais diversas, como o que vestir ou onde passear. É aí que a mídia contribui para direcionar certos debates e ajuda a orientar as decisões das pessoas, esclarecendo situações e mostrando realidades que, sem a ajuda da imprensa, poderiam se manter incompreensíveis ou desconhecidas para uma parcela da sociedade. A mídia também é a responsável por trazer à tona temas da sociedade relevantes para o debate público (MCCOMBS, 2009), tais como a inflação, o desemprego, a educação e a saúde, bem como as decisões dos governantes sobre o rumo da nação. Ao abordar estes e outros temas, o jornalismo, além de veicular as informações com precisão, também trabalha de forma clara e objetiva, para possibilitar que as pessoas de todas as classes sociais possam entender como os fatos vão acontecendo e se desenrolando (GOMES; CABRAL, 2011).

Já em relação à forma de pensar a opinião pública e às pesquisas de opinião, Figueiredo e Cervellini (1995, p. 175) consideram que "os críticos das pesquisas não aceitam que igualemos todas as opiniões individuais, dando o mesmo peso para segmentos mais ou menos politizados, organizados, influentes, escolarizados ou informados sobre o tema pesquisado". Com isso os autores pretendem reafirmar que a opinião pública pode se originar de diversas formas, como por meio de "grupos organizados, das manifestações mais ou menos espontâneas, das pesquisas, das eleições, dos comícios, das discussões em reuniões sociais, dos meios de comunicação e etc.” (FIGUEIREDO; CERVELLINI, 1995, p. 177).

Os autores Figueiredo e Cervellini (1995) e Gomes e Cabral (2011) acreditam que o primeiro passo para a formação da opinião pública é o consenso entre um grupo de pessoas. Lippmann (2010) descreve como a imprensa tem a capacidade de trazer à tona um mundo ainda desconhecido para a sociedade. As imagens de acontecimentos que não poderiam ser vistos ou vivenciados pelo público podem ser por eles construídas quando a imprensa se 
BORGES, R. F. Redes sociais, jornalismo e eleições locais em 2016: o Facebook como espaço de visibilidade da política e dos políticos nos jornais $O$ Estado do Maranhão (MA) e A Tarde (BA)

coloca à disposição para torna-los públicos. Sobre a perspectiva de pensamento de Lippmann (2010), pode-se ressaltar que a imprensa também tem uma boa participação na construção do debate sobre os temas políticos, o que justifica olhar para o modo como ela - seja em meios convencionais ou tecnológicos — aborda os temas de interesse público.

McCombs (2009) fala dessa contribuição do jornalismo ao agendar o debate em épocas de período eleitoral. Ao colocar em evidência notícias sobre os candidatos, seja de forma positiva ou negativa para a imagem de cada um deles, a imprensa contribui para que o público possa formar suas opiniões a respeito de várias situações que os eleitores podem vivenciar no período eleitoral. Quando os jornais, por exemplo, concedem muito espaço para tratar de um tema como a corrupção, em que um político concorrente ao cargo eletivo está envolvido, a mídia está agendando o debate da sociedade acerca deste assunto. E a opinião pública é gerada de acordo com a cobertura jornalística produzida pela imprensa, de forma que a mídia se torna responsável por criar uma ligação entre um determinado mundo, que poderia ser desconhecido pelo público, caso o jornalismo não se encarregasse de torná-lo claro para os leitores, e a população.

Segundo McCombs (2009), o agendamento ocorre quando a imprensa faz uma cobertura recorrente- acerca de um determinado tema, e a influência da mídia aumenta quando as eleições se aproximam. Quanto mais os meios de comunicação pautam as eleições e os temas políticos, mais esses assuntos se tornam importantes para a sociedade, conforme McCombs (2009). Dessa forma, a imprensa vai instigar a formação da opinião pública sobre aquilo que ela veicula. Inclusive, os candidatos aos quais a mídia tende a dar maior visibilidade se tornam mais conhecidos, seja a partir de uma abordagem positiva ou negativa. Os estudos de Aldé, Figueiredo e Mendes (2007) mostram como os jornais podem dar maior ou menos visibilidade aos fatos que envolvem os candidatos.

\section{O JORNALISMO E INTERESSE PÚBLICO}

A defesa pela veiculação de notícias que sejam de interesse da maioria da população é o que impulsiona os profissionais do jornalismo a irem buscar acontecimentos cujo conhecimento possa contribuir com a vida da maioria das pessoas, para que a sociedade se mantenha informada sobre o mundo que a cerca.

O direito de ser informado é garantido a todos os cidadãos na Declaração Universal de Direitos do Homem, instituída pelas Organizações das Nações Unidas (ONU) (MACHADO; MOREIRA, 2005). Porém, nem sempre o jornalista encontra facilidades no 
exercício da profissão, como aponta Karam (2004). Embora o conceito de "interesse público", no jornalismo, esteja relacionado à publicação de informações que interessem à maioria das pessoas, os dilemas de caráter ético e editorial podem influenciar na tomada de decisão dos repórteres.

Portanto, ficar dividido entre o que tornar público ou não é recorrente na atividade jornalística. A prática da vida profissional permite ao jornalista compreender como identificar o que pode e merece ganhar veiculação na imprensa. Em meio a uma imensidade de acontecimentos, Sousa (2005) observa que os jornalistas são habilitados para perceber o que realmente é válido para ser noticiado ou não. $\mathrm{O}$ autor ainda indica que os jornalistas são os agentes capacitados para coletar, editar e publicar as notícias que serão lançadas pelos veículos de comunicação e, depois, consumidas pelo público.

Cabe, portanto, ao jornalista identificar o que é de interesse público e capturar os fatos a serem noticiados, levando em consideração o que é de interesse para a maioria das pessoas. Partindo da percepção de que os jornalistas conseguem diferenciar o que é do interesse público, Weber e Coelho (2001) mostram que a informação é um bem público e que os jornalistas devem ser instruídos sobre a responsabilidade que eles adquirem ao produzir e difundir as informações para a sociedade.

Lage (2014) também ressalta o comprometimento que o jornalista, ao trabalhar nos meios de comunicação, deve ter com o interesse público, e a importância de levar em consideração as questões éticas que norteiam a profissão:

O jornalista deve saber selecionar o que interessa e é útil ao público (o seu público, o público-alvo); buscar a associação entre essas duas qualidades, dando à informação veiculada a forma mais atraente possível; ser verdadeiro quanto aos fatos (verdade, aí, é a adequação perfeita do enunciado aos fatos, adaequatio intellectus ad rem) e fiel quanto às ideias de outrem que transmite ou interpreta; admitir a pluralidade de versões para o mesmo conjunto de fatos, o que é um breve contra a intolerância; e manter compromissos éticos com relação a prejuízos causados a pessoas, coletividades e instituições por informação errada ou inadequada a circunstâncias sensíveis. (LAGE, 2014, p. 21).

Machado e Moreira (2005) acrescentam, ainda, a veiculação da informação como direito do público como algo essencial nas sociedades consideradas democráticas, pois, segundo os autores, todos os cidadãos têm o direito de serem informados corretamente, principalmente pelos meios de comunicação que dispõem de concessões públicas para funcionar. Dessa forma, vários tipos de conteúdo, como educação, saúde e cultura, tornam-se fundamentais para o bom desenvolvimento de uma sociedade. Por isso, a imprensa deve ter o compromisso de veiculá-los. Os temas eleitorais também se configuram como assuntos que 
BORGES, R. F. Redes sociais, jornalismo e eleições locais em 2016: o Facebook como espaço de visibilidade da política e dos políticos nos jornais $O$ Estado do Maranhão (MA) e A Tarde (BA)

interessam para a maioria da população. O período eleitoral, no Brasil, é um dos momentos em que os brasileiros exercem sua cidadania e escolhem as pessoas que os representarão. Este período gera conteúdos de interesse público, sejam eles notícias provocadas ou não pelos candidatos, e a imprensa, por sua vez, desempenha um papel crucial na mobilização da opinião pública (MCCOMBS, 2009).

O interesse do público anda em contraponto com o interesse público (KARAM, 2004) quando as demandas do público são levadas em consideração e as preferências da audiência passam a influenciar as decisões nas redações. Dessa forma, cada vez mais assuntos considerados "mais frios" (soft news), como entretenimento, por exemplo, tomam conta do noticiário, em detrimento das notícias "mais quentes" (hard news), assuntos mais factuais (JOHNSON, 2015). Assim, o papel dos meios de comunicação como influenciadores do debate fica comprometido. Isso será observado nesta pesquisa quando se comparar a presença de temas político-eleitorais com a de outros temas — de modo geral, de entretenimento — nas páginas dos jornais no Facebook, o que acaba mostrando o que é priorizado por tais veículos ao se distribuir notícias aos leitores.

\section{CONTEÚdo JORNALÍSTICO E A TRANSIÇÃo PARA AS REDES SOCIAIS DIGITAIS}

O uso da internet no Brasil para fins de visibilidade política dos candidatos teve início na corrida presidencial de 2002. Foi uma eleição considerada agressiva pelos analistas políticos, com ataques e difamações entre os próprios candidatos (ALDÉ; BORGES, 2004). Neste ano, a internet começa a figurar como alternativa para os candidatos ganharem visibilidade, sendo que ela, segundo Aldé e Borges (2004), amplificou e incorporou, de forma mais intensa, uma nova modalidade de fazer campanha política no Brasil. A partir de então, as campanhas passaram a ter como aliado o ambiente digital e, mais adiante, as redes sociais digitais, de forma que os candidatos ganharam, além da imprensa tradicional, outro canal de comunicação com os eleitores.

Por meio de análises das coberturas jornalísticas em períodos eleitorais, pode-se identificar como os jornais dão visibilidade aos temas de interesse público, principalmente quando se fala em política e eleições. No período de campanha política, há vários fatores que contribuem para o desempenho dos candidatos que concorrem ao pleito. Pode-se incluir diversos fatores no quesito da variação na intenção de votos entre os candidatos, como o 
programa eleitoral de cada um e os acontecimentos sociais e políticos contextuais, além da cobertura jornalística que a imprensa realiza (TAVARES; MASSUCHIN, 2015).

Em relação à presença da mídia no cotidiano das pessoas, inclusive no que diz respeito à influência que ela têm no processo de tomada de decisões do público, conforme já esboçado por McCombs (2009), a imprensa também ocupa um lugar de destaque, ao dar voz aos atores envolvidos no processo político. McCombs (2009) utiliza, basicamente, as plataformas tradicionais nos testes empíricos, para verificar como ocorre, ali, o processo de agendamento. Já Cervi e Barreta (2014) apontam para uma nova perspectiva de agendamento dos meios de comunicação — agora nas redes sociais.

De acordo com Zago e Bastos (2013), a circulação da informação se aprimorou e ganhou novos horizontes com as mídias digitais. Se antes a informação estava à disposição apenas do jornal impresso, por exemplo, agora, além deste meio de comunicação mais tradicional, uma mesma notícia pode atingir muito mais pessoas, a partir das métricas utilizadas pelo Facebook. O "comentário", a "curtida" e o "compartilhamento" fazem com que uma publicação alcance cada vez mais pessoas, e que os "amigos dos amigos", interconectados, também sejam atingidos pela mensagem (ZAGO; BASTOS, 2013).

Como os candidatos desenvolvem ações que interessam para a maioria das pessoas, a agenda da mídia passa a girar em torno do que eles realizam (MCCOMBS, 2009). Além do mais, quando as redes sociais são apropriadas como forma de veiculação de informações para os candidatos nas campanhas eleitorais, entende-se, a partir daí, um novo ambiente para divulgação das propostas das campanhas eleitorais, além de um novo espaço para que os candidatos ganhem visibilidade (MARQUES, 2012).

No processo eleitoral, os meios de comunicação se tornam uma das principais formas que os políticos têm para poder disseminar informações aos cidadãos, conforme Silva e Pellizzaro (2015). As redes sociais também entram nesse contexto. Prova disso é o número crescente de pesquisas que analisam e evidenciam tanto a sua importância, como as estratégias utilizadas na rede social durante as campanhas políticas (CERVI; BARRETA, 2014; TAVARES; MASSUCHIN, 2015; MASSUCHIN; CARVALHO, 2016).

As redes sociais também surgem como uma possibilidade de que os veículos de comunicação possam disseminar o conteúdo jornalístico, e uma oportunidade a mais de se alcançar leitores e conquistar novos públicos. O Facebook ganha atenção especial por começar a ser utilizado como uma alternativa para a difusão de conteúdos jornalísticos. O uso desta rede como dispositivo de veiculação de conteúdos noticiosos já é explorado por vários jornais país afora, conforme identificou Dalmaso (2012), quando analisou o jornal A Razão 
BORGES, R. F. Redes sociais, jornalismo e eleições locais em 2016: o Facebook como espaço de visibilidade da política e dos políticos nos jornais $O$ Estado do Maranhão (MA) e A Tarde (BA)

da cidade de Santa Maria (RS). Segundo a autora, "os sites de redes sociais ampliaram o sistema de difusão e circulação de informações, horizontalizando o jornalismo na medida em que as empresas perdem o total controle que tinham sobre a produção de informação" (DALMASO, 2012, p. 2).

Já em relação à última eleição presidencial ocorrida no Brasil, em 2014, Tavares e Massuchin (2015) analisaram como os candidatos que concorriam ao cargo de Presidente da República, na época, utilizaram o Facebook com estratégias eleitorais. Já as autoras Zago e Bastos (2013), ao analisarem como as notícias circulam nas redes sociais - Facebook e Twitter - dos jornais da Europa e da América, perceberam que as redes sociais podem ser uma alternativa para que os leitores passem, cada vez mais, a visitar os sites dos jornais.

\section{ASPECTOS METODOLÓGICOS}

Esta pesquisa é um recorte de uma pesquisa maior, na qual se analisam as postagens de nove jornais do Nordeste brasileiro. Como recorte, aqui serão analisadas as páginas do Facebook dos jornais $\mathrm{O}$ Estado do Maranhão (MA) e A Tarde (BA) ${ }^{7}$. Os dados foram extraídos por meio do aplicativo Netvizz, sendo eles 9.993 postagens dos nove jornais analisados pelo Grupo de Pesquisa em Comunicação, Política e Sociedade (COPS), na pesquisa anterior. Os jornais O Estado do Maranhão (MA) e A Tarde (BA) foram escolhidos para esta pesquisa porque representam o maior e o menor dentre os nove jornais analisados, respectivamente, levando-se em consideração a sua circulação e visibilidade na versão impressa, devido à centralidade do veículo para a cidade e o estado de que fazem parte os jornais analisados. No que diz respeito a esses dois jornais, foram 1.871 as postagens analisadas. A campanha eleitoral de $2016^{8}$ para o primeiro turno foi mais curta em relação aos anos anteriores, correspondendo a apenas sete semanas, do dia 16 de agosto a 2 de outubro.

A metodologia utilizada neste trabalho é a quantitativa de análise de conteúdo. Optou-se pela metodologia quantitativa devido ao número relativamente grande de postagens coletadas, além do fato de o período de análise ser bastante extenso. Sobre a aplicação do método de análise de conteúdo, Herscovitz (2008) destaca sua importância pela capacidade que o método tem de avaliar um número grande de informações, cujas regras estejam explícitas e definidas. Ainda de acordo com as definições de Herscovitz (2008), o método de

\footnotetext{
${ }^{7}$ https://www.facebook.com/jornaloestadoma/ e https://www.facebook.com/atarde.online/.

${ }^{8}$ http://www.tse.jus.br/imprensa/noticias-tse/2016/Janeiro/conheca-as-novas-regras-das-eleicoes-municipaisde-2016
} 
análise de conteúdo é possível a partir da compilação dos objetos estudados - neste caso, o recolhimento dos posts de cada jornal, que depois foram enquadrados em categorias já testadas.

Cervi e Massuchin (2013) compreendem ser necessário monitorar os conteúdos veiculados pelos meios de comunicação, principalmente nos períodos eleitorais, para aferir a qualidade das informações que a população está recebendo por meio deles, além de se poder explicar a importância da imprensa nos períodos eleitorais. Bauer (2002) afirma que a análise de conteúdo é relevante quando em meio a uma análise estatística de várias unidades de texto, quando é possível classificar de forma sistemática estas unidades, contribuindo-se para a descrição das características do material coletado.

As postagens relacionadas à disputa eleitoral de 2016 foram enquadradas de acordo com o livro de codificação utilizado pelo grupo de pesquisa, a partir das seguintes variáveis, utilizadas para esta análise: "tema geral"”; "tema específico de campanha"10"; "presença do candidato"; e "valência dos candidatos ${ }^{11}$ ", que diz respeito à análise sobre o modo como foram mencionados - de forma positiva, negativa, neutra ou informativa. A análise a ser apresentada no tópico seguinte compara o modo como os dois jornais se comportam no Facebook em relação a essas quatro características.

Em termos de contextualização do objeto, o jornal A Tarde pertence ao Grupo A Tarde de comunicação, e fica localizado na cidade de Salvador (BA). Além de ser um dos maiores jornais do estado, em 2016 o jornal completou 104 anos de existência, em 15 de outubro, sendo veiculado na versão impressa e contando com uma circulação de mais de 28

\footnotetext{
${ }^{9}$ Dividida entre Campanha eleitoral ou partidos; Político-institucional; Economia; Saúde; Educação; Minorias; Infraestrutura urbana; Meio ambiente; Violência e segurança; Acidentes e tragédias; Ético-moral; Variedades e cultura; Curiosidades; Esportes; outros temas ou ausência de informação jornalística/apenas interação.

${ }^{10}$ Dividida entre as categorias Agenda de campanha, onde foram levados em consideração os compromissos dos candidatos; Imagem política do candidato, em que eram evidenciadas as menções ao candidato como político ou membro do partido; Imagem pessoal do candidato, quando se falava no político como pai, filho, marido ou estudante; Imagem administrativa do candidato, quando as publicações falavam sobre ele como gestor público ou administrador; Imagem do partido, quando se fazia referência aos partidos e decisões partidárias; Informações da campanha, em relação aos prazos, mudanças e regras da disputa eleitoral; Justiça eleitoral, sobre as decisões da justiça eleitoral; Resultado da pesquisa, quando eram divulgados os resultados das pesquisas eleitorais; e, por fim, Outros, quando as postagens não se enquadravam em nenhuma das variáveis citadas anteriormente.

${ }^{11}$ Positiva: o texto aborda ações de iniciativa do candidato; declarações de terceiros favoráveis ao candidato (no que diz respeito a avaliações de ordem moral, política ou pessoal) e/ou às suas propostas de governo; e divulgação de resultados de pesquisas ou estudos favoráveis ao candidato. Negativa: publicação com ressalvas, críticas e/ou ataques (de ordem moral, política ou pessoal) do autor ou de terceiros ao candidato ou às suas propostas; divulgação de resultados de pesquisas ou estudos desfavoráveis à candidatura; e divulgação de denúncias, como corrupção, envolvendo o candidato e/ou seu partido, ressaltando-se evidências contra ele. Neutra: agenda do candidato; citação sem avaliação moral, política ou pessoal; e simples reprodução de resultados de campanha, sem avaliações em relação à posição do candidato. Informações de campanha: não há avaliação moral, política ou pessoal sobre o candidato - matérias com relatos sobre a agenda do candidato, sem tratar de seus pontos negativos ou positivos e sem apresentar suas promessas de campanha.
} 
BORGES, R. F. Redes sociais, jornalismo e eleições locais em 2016: o Facebook como espaço de visibilidade da política e dos políticos nos jornais $O$ Estado do Maranhão (MA) e A Tarde (BA)

mil exemplares, segundo os dados da Associação Nacional dos Jornais (ANJ), em 2015. Figurando como o que mais possui circulação impressa entre os nove jornais pesquisados no Nordeste, o jornal A Tarde está presente nas redes sociais no Facebook e no Twitter. Na página do Facebook, o jornal possui mais de 180 mil seguidores. Na versão online, está disponível no endereço www.atarde.uol.com.br.

Já o jornal O Estado do Maranhão faz parte do Grupo Mirante de comunicações e circula diariamente pela manhã, há mais de 50 anos. É o maior periódico do estado, trabalhando em conjunto com o portal de notícias Imirante.com, na produção de notícias jornalísticas (www.imirante.com/oestadoma/). O jornal também possui contas no Twitter e no Instagram e uma página no Facebook, com mais de 80 mil curtidas em março de 2017. No Facebook, as notícias são postadas de acordo com o que é produzido pelo site do jornal, que fica hospedado no mesmo site do portal Imirante. O jornal O Estado do Maranhão é considerado o menor dentre os nove jornais analisados, em relação à circulação do periódico impresso, e, por isso, não consta na lista da ANJ sobre a circulação dos jornais brasileiros.

\section{COMPORTAMENTO DOS JORNAIS NO FACEBOOK E A COBERTURA POLÍTICA}

A cobertura jornalística realizada pelos jornais A Tarde (BA) e O Estado do Maranhão (MA), entre os meses de agosto e outubro de 2016, contou com 1.871 postagens realizadas pelos dois periódicos. O total de publicações corresponde a uma média de 30 postagens por dia durante as sete semanas do período eleitoral. 


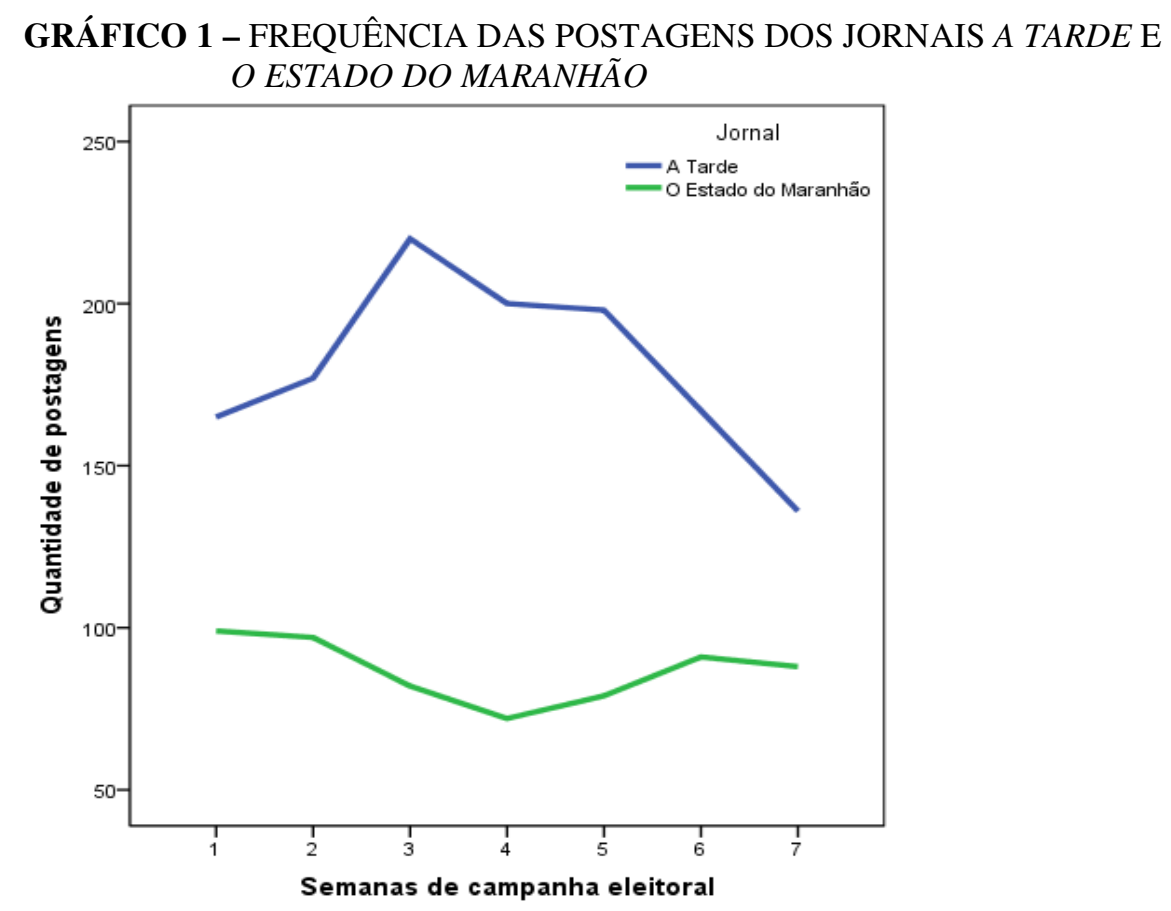

FONTE: GRUPO DE PESQUISA EM COMUNICAÇÃO, POLÍTICA E SOCIEDADE (2016).

Os jornais A Tarde e O Estado do Maranhão apresentaram características bem distintas, como mostra o gráfico acima, quanto ao número de postagens realizadas durante as sete semanas que antecederam o primeiro turno — de 16 de agosto a 2 de outubro — das eleições municipais em 2016. O jornal A Tarde teve um número expressivo de publicações no Facebook, correspondendo a um total de 1.262 postagens na rede social, neste período. Já O Estado do Maranhão teve um menor número de posts, se comparado ao A Tarde. O Estado fez, no mesmo período, 602 publicações, o que permite entender que o jornal tem, no Maranhão, uma frequência de postagem relativamente menor que o periódico da Bahia.

Quanto à frequência das postagens feitas pelos jornais, o jornal A Tarde, além de ter um número alto de publicações, não mostrou ter uma tendência quanto à regularidade das postagens. Na primeira semana de análise, manteve uma média de 150 publicações, mas diminui o ritmo na sétima semana, diminuindo a quantidade de postagem para menos de 130 . Ainda, o periódico apresentou uma elevação nas publicações na segunda semana, com mais de 220 publicações. Entre os assuntos que proporcionaram esse aumento de postagens, destacam-se o processo de impeachment da presidente Dilma Rousseff e as eleições municipais. Já O Estado do Maranhão demonstrou conseguir manter um padrão quanto à regularidade das publicações. O jornal manteve, em média, 100 postagens por semana, durante as sete semanas analisadas. Na quarta semana, O Estado apresentou uma baixa quanto à frequência das publicações, indo para quase 70. Quanto ao número de postagens dos dois 
BORGES, R. F. Redes sociais, jornalismo e eleições locais em 2016: o Facebook como espaço de visibilidade da politica e dos políticos nos jornais O Estado do Maranhão (MA) e A Tarde (BA)

periódicos, houve uma diminuição das publicações enquanto se aproximavam as eleições para o primeiro turno. O jornal A Tarde foi o que mais diminuiu a quantidade de postagens.

\section{GRÁFICO 2 - TEMAS DAS POSTAGENS DO JORNAL A TARDE}

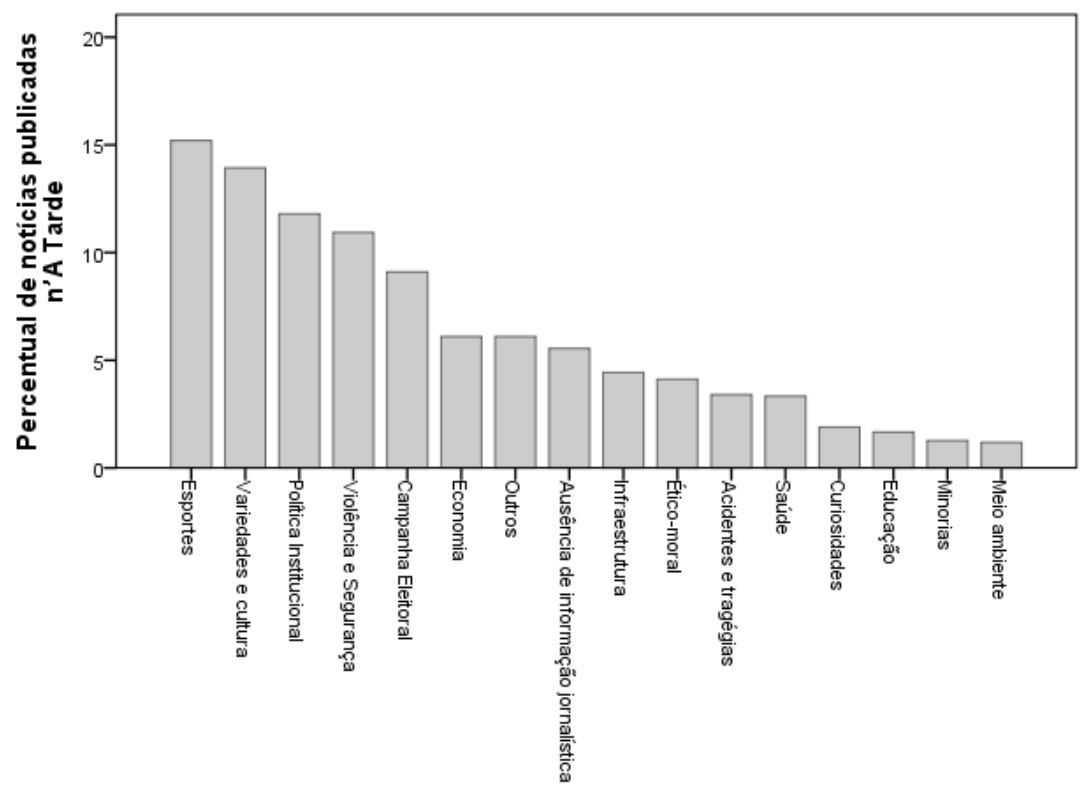

FONTE: GRUPO DE PESQUISA EM COMUNICAÇÃO, POLÍTICA E SOCIEDADE (2016).

O gráfico acima mostra a quais temas o jornal A Tarde deu destaque durante a cobertura jornalística no período da campanha eleitoral. As pautas soft news, foram as que mais tiveram publicações no jornal, estando entre elas os posts relacionados a temas como "esportes" $(15,2 \%)$ e "variedades e cultura" $(13,9 \%)$. Sobre a frequência dos temas soft na cobertura dos jornais, Zago e Bastos (2013) ponderam que é comum que o Facebook conceda mais espaço para temas deste tipo. Já os assuntos relacionados à campanha eleitoral $(9,1 \%)$ figuram como o quarto tema que mais aparece no período. Os assuntos considerados hard news tiveram pouco espaço na cobertura jornalística do A Tarde, estando entre eles "educação" (1,7\%) e "saúde" (3,3\%). De acordo com Bronoski, Barreta e Cervi (2010), os conteúdos hard, como temas de interesse público, contribuem bem mais para o debate na sociedade, ao contrário dos temas soft, que possuem um apelo mais comercial, pois são conteúdos que agradam mais aos leitores e contribuem para gerar acessos na página do jornal.

O Gráfico 3, referente aos temas das publicações do jornal O Estado do Maranhão, mostra o tema "campanha eleitoral" $(17,4 \%)$ como o que mais obteve espaço na página do Facebook do jornal, atrás apenas de "política institucional" (21,2\%). Os temas hard, como "violência e segurança" (12,3\%), "economia" (7,6\%) e "infraestrutura" (6,9\%), tiveram 
destaque na cobertura d'O Estado. Os temas soft, como "esporte" (2,3\%) e "curiosidades" (3\%), tiveram pouco destaque. O uso das redes sociais para a disseminação de conteúdos de entretenimento e de interesse público também foi demonstrado por Zago e Bastos (2013).

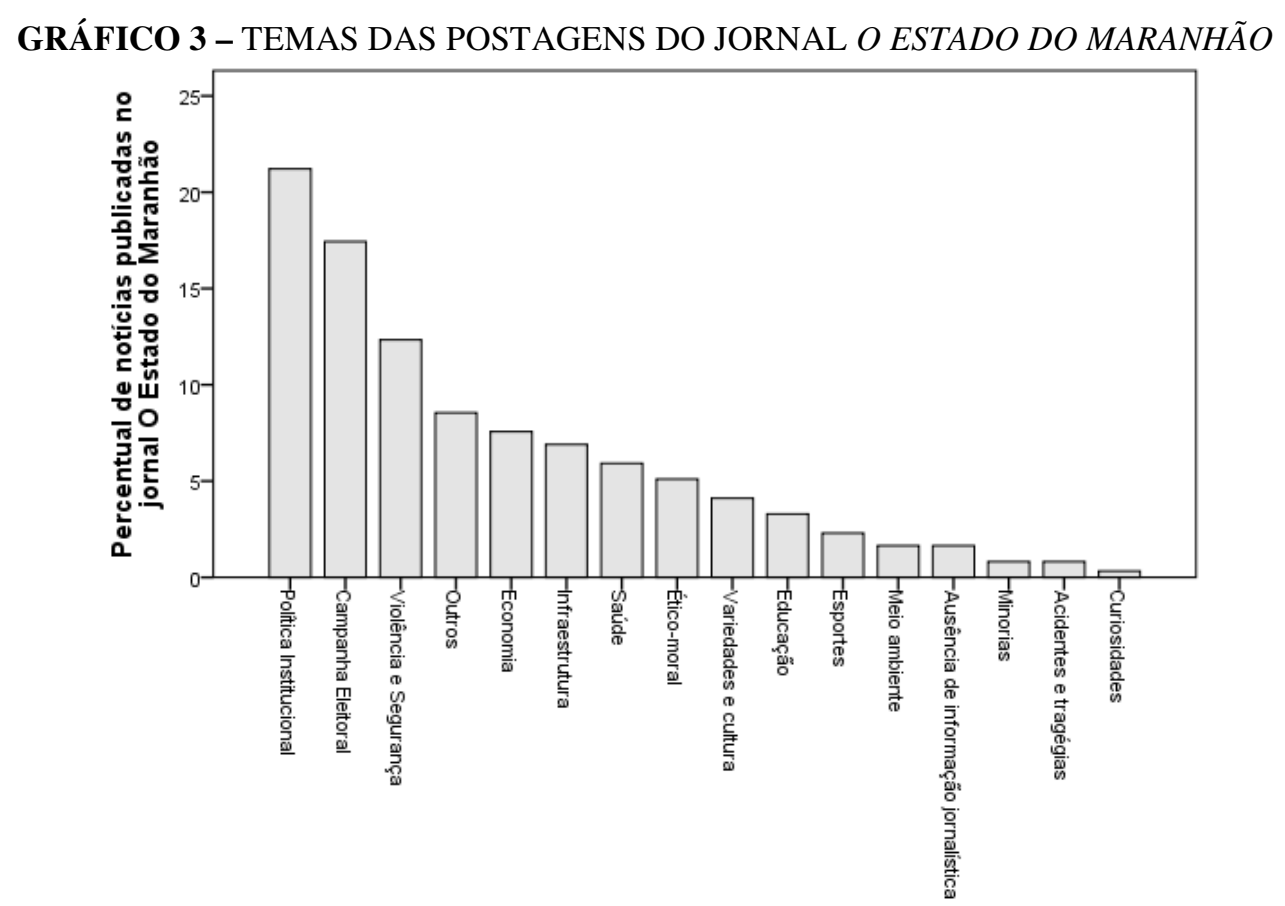

FONTE: GRUPO DE PESQUISA EM COMUNICAÇÃO, POLÍTICA E SOCIEDADE (2016).

Traquina (2005) considera que a escolha dos assuntos que serão veiculados nos jornais pelos jornalistas tem como motivação ora a interpretação que tais profissionais fazem dos acontecimentos, ao pensarem se os temas têm relevância ou não para a população, ora as pressões editoriais ainda presentes nas redações. Sobre os temas que os dois jornais levaram para as redes sociais, O Estado do Maranhão ofereceu muito espaço da cobertura jornalística às questões referentes à campanha política de 2016, como se percebe pela presença acentuada do tema "campanha eleitoral" no Gráfico 2, enquanto o jornal A Tarde pouco falou do assunto.

\section{INFORMAÇÃO DE CAMPANHA E A VISIBILIDADE DOS CANDIDATOS}

Nesta parte do artigo será analisada a presença dos candidatos nos posts de cada jornal, de acordo com o tratamento que eles receberam - positivo, negativo, neutro ou equilibrado. Também se analisará quais os candidatos que ganharam visibilidade na cobertura 
BORGES, R. F. Redes sociais, jornalismo e eleições locais em 2016: o Facebook como espaço de visibilidade da politica e dos políticos nos jornais O Estado do Maranhão (MA) e A Tarde (BA)

jornalística realizada pelos jornais, além de apontar as diferenças e similaridades a respeito da cobertura de cada veículo de comunicação.

TABELA 1 - TEMA DAS POSTAGENS DOS JORNAIS A TARDE E O ESTADO DO MARANHÃO

\begin{tabular}{c|c|c|c|c|c|c}
\cline { 2 - 7 } & \multicolumn{3}{c|}{ A Tarde } & \multicolumn{3}{c}{ O Estado do Maranhão } \\
\cline { 2 - 7 } & Frequência & Percentual & $\begin{array}{c}\text { Percentual } \\
\text { válido }\end{array}$ & Frequência & Percentual & $\begin{array}{c}\text { Percentual } \\
\text { válido }\end{array}$ \\
\hline Agenda/eventos de campanha & 29 & 2,3 & 25,2 & 38 & 6,3 & 35,8 \\
\hline Imagem política do candidato & 9 & 0,7 & 7,8 & 2 & 0,3 & 1,9 \\
\hline Imagem administrativa do candidato & 9 & 0,7 & 7,8 & 6 & 1 & 5,7 \\
\hline Imagem dos partidos & 5 & 0,4 & 4,3 & 3 & 0,5 & 2,8 \\
\hline Informações da campanha & 15 & 1,2 & 13 & 11 & 1,8 & 10,4 \\
\hline Resultados de pesquisas & 5 &, 4 & 4,3 & 12 & 2,0 & 11,3 \\
\hline Justiça eleitoral & 14 & 1,1 & 12,2 & 8 & 1,3 & 7,5 \\
\hline Outro & 29 & 2,3 & 25,2 & 26 & 4,3 & 24,5 \\
\hline Total & 115 & 9,1 & 100 & 106 & 17,4 & 100 \\
\hline Total & & & & & & \\
\hline
\end{tabular}

FONTE: GRUPO DE PESQUISA EM COMUNICAÇÃO, POLÍTICA E SOCIEDADE (2016).

No universo de 1.263 postagens analisadas no jornal A Tarde, onde estão englobados todos os posts realizados pelo veículo, destacam-se os subtemas que tratam apenas da campanha eleitoral de 2016, num total de 115 publicações. Dentre eles, a agenda dos candidatos $(25,2 \%)$ foi o tema que mais recebeu atenção, seguido do tema "informações da campanha" (13\%) como o segundo conteúdo mais publicado pelo jornal. A justiça eleitoral $(12,2 \%)$ foi o terceiro tema que mais ganhou visibilidade, seguido das temáticas "imagem política do candidato" e "imagem administrativa do candidato", que representaram, cada uma, $7,8 \%$ dos assuntos publicados, enquanto "resultados de pesquisas" e "imagem dos partidos" representaram, individualmente, $4,3 \%$.

Agora, analisando os mesmos temas no jornal O Estado do Maranhão, nos 106 posts que dizem respeito apenas a campanha eleitoral, o tema de maior destaque foi "agenda/eventos de campanha" (35,8\%), seguido de "resultados de pesquisas" (11,3\%) e “informações da campanha" (10,4\%). Como assuntos que receberam pouca atenção do jornal no período analisado, "justiça eleitoral” (7,5\%) figura como o quarto assunto de menor destaque, vindo em seguida "imagem administrativa do candidato", "imagem dos partidos" e "imagem política do candidato", com 5,7\%, 2,8\% e 1,9\%, respectivamente.

Pode-se destacar, por meio dos dados aqui expostos, como característica comum aos dois jornais, uma grande dependência da agenda dos candidatos para a cobertura jornalística dos fatos noticiosos. Sobre esse tipo de comportamento da imprensa, Cervi (2003) afirma que, quando a cobertura é focada apenas no dia a dia dos candidatos e nos eventos produzidos por 
eles, os jornais fazem uma cobertura limitada do período eleitoral. Porém, esta não é uma postura exclusiva dos jornais do Nordeste, conforme demonstra Cervi (2003). Ao analisar os jornais de circulação nacional nas eleições presidenciais de 2002, o autor percebeu que eles também focavam na agenda dos candidatos. Ainda, podemos destacar a baixa atenção que os dois jornais aqui analisados deram à imagem política e pessoal dos candidatos, quando poderiam ter sido destacados seus feitos políticos, além de ter sido feito um melhor esboço das suas propostas aos eleitores.

TABELA 2 - PRESENÇA DOS CANDIDATOS NOS JORNAIS A TARDE E O ESTADO DO MARANHÃO

\begin{tabular}{l|l|c|c}
\cline { 3 - 3 } \multicolumn{2}{c|}{} & Frequência & Percentual \\
\hline \multirow{4}{*}{ A Tarde } & Não menciona nenhum candidato & 1225 & 97 \\
\cline { 2 - 4 } & Faz menção a algum candidato & 38 & 3 \\
\cline { 2 - 4 } & Total & 1263 & 100 \\
\hline \multirow{4}{*}{ O Estado do Maranhão } & Não menciona nenhum candidato & 558 & 91,8 \\
\cline { 2 - 4 } & Faz menção a algum candidato & 50 & 8,2 \\
\cline { 2 - 4 } & Total & 608 & 100 \\
\hline
\end{tabular}

FONTE: GRUPO DE PESQUISA EM COMUNICAÇÃO, POLÍTICA E SOCIEDADE $\overline{(2016) .}$

A Tabela 2 mostra a quantidade de textos publicados nos jornais que mencionavam algum candidato no período de análise. Por motivos de padronização, foram considerados apenas os três primeiros citados em cada texto em que aparecia algum candidato. Levando em consideração as 1263 postagens feitas pelo jornal A Tarde, apenas 3\% das publicações faziam alguma menção aos candidatos. A quantidade de publicações sem nenhuma referência aos políticos somou $97 \%$ da cobertura jornalística feita pelo jornal.

Já o jornal O Estado do Maranhão, em contrapartida, destinou mais espaço aos concorrentes do pleito eleitoral. Das 608 posts, que representam todas as publicações realizadas pelo jornal na época das eleições, no mesmo período, 8,2\% de todas as publicações mencionavam algum candidato. Os demais textos do jornal, que não se reportavam aos candidatos, correspondem a 91,8\% da cobertura jornalística do veículo, dentre as notícias que se referem à campanha eleitoral. 
BORGES, R. F. Redes sociais, jornalismo e eleições locais em 2016: o Facebook como espaço de visibilidade da política e dos políticos nos jornais O Estado do Maranhão (MA) e A Tarde (BA)

TABELA 3 - VALÊNCIA DOS CANDIDATOS DOS JORNAIS A TARDE E $O$ ESTADO DO MARANHÃO

\begin{tabular}{l|c|c|c|c}
\hline \multirow{2}{*}{} & \multicolumn{2}{|c|}{ A Tarde } & \multicolumn{2}{c}{ O Estado do Maranhão } \\
\cline { 2 - 5 } & Número & Percentual & Número & Percentual \\
\hline Positivo & 13 & 26 & 13 & 19 \\
\hline Negativo & 11 & 22 & 12 & 18 \\
\hline Neutro & 20 & 40 & 43 & 63 \\
\hline Equilibrado & 6 & 12 & 0 & 0 \\
\hline Total & 50 & 100 & 68 & 100
\end{tabular}

FONTE: GRUPO DE PESQUISA EM COMUNICAÇÃO, POLÍTICA E SOCIEDADE (2016).

Para avaliar o tratamento dado aos candidatos de forma conjunta, analisou-se a valência das publicações, o que permite identificar se a cobertura da campanha foi feita de forma positiva, negativa, neutra ou equilibrada. De acordo com a Tabela 3, o jornal A Tarde concedeu aos candidatos, na cobertura noticiosa das redes sociais, $40 \%$ de tratamento neutro. As posturas positiva e negativa do jornal A Tarde em relação aos candidatos correspondem a $26 \%$ e $22 \%$, respectivamente, enquanto as postagens equilibradas representam $12 \%$. Em O Estado, as aparições neutras dos políticos também são as maiores, em um total de $63 \%$ da cobertura. O tratamento positivo corresponde a $19 \%$, e o negativo a $18 \%$. Não há nenhuma menção equilibrada aos concorrentes. Como se pode perceber, O Estado tem uma postura mais neutra em relação ao jornal A Tarde, que tem uma melhor divisão quanto aos tratamentos positivo e negativo dos candidatos.

A próxima tabela apresenta os candidatos que mais apareceram nos dois jornais, enfatizando quais deles tiveram mais visibilidade durante a cobertura jornalística do período eleitoral realizada pelos jornais A Tarde e O Estado do Maranhão no Facebook.

TABELA 4 - VISIBILIDADE DOS CANDIDATOS NOS JORNAIS A TARDE E O ESTADO DO MARANHÃO

\begin{tabular}{l|l|c|c}
\hline \multirow{2}{*}{ Jornal } & \multicolumn{1}{|c|}{ Candidato } & Frequência & Percentual válido \\
\hline \multirow{5}{*}{ A Tarde } & \multicolumn{1}{|c|}{ ACM Neto } & 25 & 50 \\
\cline { 2 - 4 } & Alice Portugal & 10 & 20 \\
\cline { 2 - 4 } & Célia Sacramento & 8 & 16 \\
\cline { 2 - 4 } & Claudio Silva & 1 & 2 \\
\cline { 2 - 4 } & Fábio Nogueira & 2 & 2 \\
\cline { 2 - 4 } & Flavio Bolsonaro & 1 & 2 \\
\cline { 2 - 4 } & Sargento Isidório & 2 & 2 \\
\cline { 2 - 4 } & Valdemir de Jesus Mota & 1 & 2 \\
\hline
\end{tabular}




\begin{tabular}{l|l|c|c}
\hline & Total & 50 & 100 \\
\hline \multirow{4}{*}{ O Estado do Maranhão } & Cláudia Durans & 4 & 5,9 \\
\cline { 2 - 4 } & Edivaldo Holanda Jr. & 23 & 33,8 \\
\cline { 2 - 4 } & Eduardo Braide & 5 & 7,4 \\
\cline { 2 - 4 } & Eliziane Gama & 9 & 13,2 \\
\cline { 2 - 4 } & Fábio Câmara & 3 & 4,4 \\
\cline { 2 - 4 } & Rose Sales & 3 & 4,4 \\
\cline { 2 - 4 } & Valdeny Barros & 5 & 7,4 \\
\cline { 2 - 4 } & Wellington do Curso & 12 & 17,6 \\
\cline { 2 - 4 } & Zeluis Lago & 4 & 5,9 \\
\cline { 2 - 4 } & Total & 68 & 100 \\
\hline
\end{tabular}

FONTE: GRUPO DE PESQUISA EM COMUNICAÇÃO, POLÍTICA E SOCIEDADE (2016).

No jornal A Tarde, os candidatos a prefeito ACM Neto (DEM), Alice Portugal (PCdoB) e Célia Sacramento (PPL) foram os que mais ganharam visibilidade. ACM Neto teve $50 \%$ das aparições na cobertura do jornal, enquanto Alice Portugal teve $20 \%$, Célia Sacramento, 16\%, Claudio Silva, 2\%, Fábio Nogueira, 4\% e Sargento Isidório, 4\%. Os outros dois candidatos, Vlademir de Jesus Mota (PV) e Flávio Bolsonaro (PSC), não pertencem à cidade de Salvador, diferentemente de todos os outros candidatos que apareceram nas postagens do jornal. No caso do candidato Flávio Bolsonaro (PSC), do Rio de Janeiro, a notícia que repercutiu foi a do mal-estar sentido pelo político em um debate, quando seu pai não aceitou a ajuda médica da candidata adversária, Jandira Feghali. O fato ganhou as redes sociais - e a página do jornal A Tarde.

No jornal O Estado do Maranhão, os candidatos mais recorrentes na cobertura jornalística foram Edivaldo Holanda (33,8\%), Wellington do Curso (17,6\%), Eliziane Gama $(13,2 \%)$, Eduardo Braide (7,4\%), Valdeny Barros (7,4\%), Cláudia Durans (5,9\%), Zeluis Lago $(5,9 \%)$ e Rose Sales $(4,4 \%)$. Um dos fatores em comum entre os dois jornais é o fato de todos os candidatos citados nas notícias serem, majoritariamente, das cidades de São Luís (capital do Maranhão e sede do jornal O Estado do Maranhão) e Salvador (capital da Bahia e cidade onde fica o jornal A Tarde). Dessa forma, uma das características da cobertura jornalística dos jornais é a centralidade nas campanhas dos candidatos que se encontram nas capitais dos estados, o que não favorece a formação do debate público acerca das eleições. Os dois jornais são os maiores tanto do Maranhão quanto da Bahia e não deram espaço para os candidatos das demais cidades. De acordo com a teoria da agenda de McCombs (2009), quanto mais as pessoas têm alguma necessidade de orientação, mais elas prestam atenção na agenda da mídia, que, nesta situação, foi uma agenda fragmentada (CERVI, 2003), pois realizou uma cobertura centrada em apenas algumas das questões referentes às eleições. 
BORGES, R. F. Redes sociais, jornalismo e eleições locais em 2016: o Facebook como espaço de visibilidade da política e dos políticos nos jornais O Estado do Maranhão (MA) e A Tarde (BA)

Outro fator importante é a ligação dos dois jornais a grupos políticos. O jornal $\mathrm{O}$ Estado do Maranhão é controlado pelo grupo Sarney (COSTA; CONCEIÇÃO, 2008), forte oligarquia política no estado do qual o jornal faz parte. Já o jornal A Tarde, em 2016, passou, após dificuldades financeiras, a ser controlado por um grupo de empresários que aceitou manter a autonomia editorial do periódico. O candidato ACM Neto (PSC) venceu ainda no primeiro turno, enquanto o candidato Edivaldo Holanda seguiu para o segundo turno das eleições. Os dois candidatos concorriam à reeleição e sempre estiveram em primeiro lugar nas pesquisas de intenção de votos. Dessa forma, os dois jornais podem ter exercido grande influência no processo decisório das eleições, sendo que, de acordo com Cervi (2003), diversas literaturas apontam o agendamento como fator importante em uma eleição, por conseguir alinhar os debates e influenciar na escolha das pessoas, independentemente de sua classe social.

Os candidatos que menos tiveram visibilidade na cobertura foram os que apresentaram uma votação menos expressiva no primeiro turno das eleições. Em relação aos candidatos citados no jornal A Tarde, o terceiro colocado, Sargento Isidório (PDT), teve apenas $4 \%$ de aparição no jornal, mas uma votação relevante, enquanto Célia Sacramento (PPL) ocupou o quarto lugar na votação do primeiro turno e foi a terceira que mais recebeu visibilidade na cobertura jornalística. Já no jornal $\mathrm{O}$ Estado do Maranhão, o candidato Edivaldo Holanda (PDT), além de ter sido o primeiro colocado no primeiro turno, foi o que mais apareceu nas postagens do jornal, com 33,8\% das aparições, enquanto Eduardo Braide (PMN), mesmo recebendo pouca visibilidade na cobertura do jornal, alcançou a segunda colocação no primeiro turno. O candidato Wellington do Curso (PP) ficou em terceiro lugar na votação, e teve uma visibilidade expressiva no jornal, com 17,6\% das aparições.

\section{CONCLUSÃO}

Este trabalho teve como objetivo analisar como os jornais O Estado do Maranhão (MA) e A Tarde (BA) fazem a cobertura jornalística no período eleitoral, além de verificar qual o tratamento que os candidatos que concorrem ao cargo de prefeito recebem dos periódicos nestes períodos.

Relembrando a discussão de McCombs (2009) sobre a teoria do agendamento e os efeitos que ela tem sobre o público, conclui-se que os dois jornais possuem agendas diferentes. Enquanto o jornal A Tarde prioriza temas soft, O Estado do Maranhão destacou, na sua cobertura, os assuntos hard. O Estado do Maranhão proporcionou aos leitores, na 
cobertura feita no Facebook, assuntos mais relevantes socialmente e que contribuem de forma efetiva para a promoção do debate na sociedade e, consequentemente, para a formação da opinião pública (MCCOMBS, 2009).

Outro ponto de destaque é o comportamento semelhante dos dois jornais na sétima semana de análise, próxima do primeiro turno das eleições, quando tiveram uma pequena quantidade de publicações. Alinhados às interpretações de Cervi (2003), os jornais aqui analisados pouco foram em busca de notícias que pudessem contextualizar o período eleitoral para os leitores, ficando centrados, na maioria das vezes, na agenda dos candidatos. Em suma, os dois jornais não foram capazes de ofertar para os eleitores uma cobertura mais sistematizada sobre a realidade política.

Outra tendência em comum das duas fanpages foi a centralização da cobertura jornalística apenas nos candidatos das capitais, com exceção da referência feita pelo jornal A Tarde a um candidato de outra cidade — e até de outro Estado —, mas de forma tímida. O Estado do Maranhão, no período de análise, não concedeu nenhum espaço de visibilidade aos candidatos que concorriam ao cargo de prefeito nas cidades do interior. Além do mais, os candidatos que mais tiveram visibilidade foram os que estavam nas primeiras colocações na votação do primeiro turno.

Os resultados aqui apresentados são parte de uma pesquisa feita em conjunto e apresentam algumas características da cobertura jornalística que a imprensa realiza, agora, nas redes sociais.

\section{REFERÊNCIAS:}

ALDÉ, A.; BORGES, J. Internet, imprensa e as eleições de 2002: pautando notícias em tempo real. Logos, Rio de Janeiro, v. 21, 2004.

ALDÉ, A.; MENDES, G.; FIGUEIREDO, M. Tomando partido: imprensa e eleições presidenciais em 2006. Política e Sociedade - Revista de Sociologia Política, Florianópolis, v. 6, n. 10, 2007. Disponível em: <https://periodicos.ufsc.br/index.php/politica/article/view/1688>. Acesso em: 17 maio 2017.

BAUER, M. Análise de conteúdo clássica: uma revisão. In: BAUER, M.; GASKELL, G. (Org.). Pesquisa qualitativa com texto, imagem e som: um manual prático. Petrópolis, RJ: Vozes, 2002.

BITAR, M. P. B.; ROCHA, L. V. Microjornalismo no Twitter: aspectos da estrutura jornalística na rede social. Temática, v. 12, n. 4, abr. 2016. Disponível em: <http://periodicos.ufpb.br/ojs2/index.php/tematica>. Acesso em: 18 abr. 2016. 
BORGES, R. F. Redes sociais, jornalismo e eleições locais em 2016: o Facebook como espaço de visibilidade da política e dos políticos nos jornais O Estado do Maranhão (MA) e A Tarde (BA)

BRASIL. Presidência da República. Relatório final Pesquisa Brasileira de Mídia - PBM 2016. Brasília: Secom, $2014 . \quad$ Disponível em: $<$ http://www.secom.gov.br/atuacao/pesquisa/lista-de-pesquisas-quantitativas-e-qualitativasde-contratos-atuais/pesquisa-brasileira-de-midia-pbm-2016.pdf/view $>$. Acesso em: 18 abr. 2016.

BRONOSKI, B.; BARRETTA, L. M.; CERVI, E. U. Debate público ou entretenimento: a visibilidade de hard e soft news nas primeiras páginas do JM e DC1. Trabalho apresentado no 33. Congresso Brasileiro de Ciências da Comunicação, Caxias do Sul, 2010. Disponível em: $<\mathrm{http}$ ///www.intercom.org.br/papers/nacionais/2010/resumos/R5-1620-1.pdf>. Acesso em: 17 maio 2017.

CERVI, E. U. A cobertura da imprensa e as eleições presidenciais 2002. BOCC - Biblioteca on-line de Ciências da Comunicação, v. 1, p. 1, 2003.

Eleições e variedades nas primeiras páginas de dois jornais regionais. Eptic Online, v. 11, n. 2, 2009.

CERVI, E. U.; MASSUCHIN, M. G. Metodologia quantitativa em pesquisas sobre cobertura jornalística: análise da eleição municipal de 2012 na Folha de S. Paulo. Revista Famecos mídia, cultura e tecnologia, Porto Alegre, v. 20, n. 3, p. 840-865, set./dez. 2013.

CERVI, E. U.; BARRETTA, L. M. Contra-agendamento na Folha de São Paulo: opinião pública e presença dos candidatos a presidente do PSDB e PT no jornal (2006 e 2010). Eptic, v. 16, n. 1, 2014. Disponível em: <https://seer.ufs.br/index.php/eptic/article/view/1866>. Acesso em: 3 abr. 2017.

COSTA, Ramon Bezerra, CONCEIÇÃO, Francisco Gonçalves da. As origens do jornal O Estado do Maranhão. Anais do Intercom, São Luís, 2008. Disponível em: http://www.intercom.org.br/papers/regionais/nordeste2008/resumos/R12-0243-1.pdf. Acesso em: 24 julho 2016.

DALMASO, S. C. Usos do facebook na publicação de conteúdo jornalístico: um estudo inicial das postagens do Jornal A Razão. Trabalho apresentado no 10. Encontro Nacional de Pesquisadores em Jornalismo, Curitiba, 2012.

FIGUEIREDO, R.; CERVELLINI, S. Contribuições para o conceito de opinião pública. Opinião Pública, Campinas, v. 3, n. 3, p.171-185, 3, dez. 1995.

GOMES, M. R.; CABRAL, N. L. S. C. Jornalismo: uma relação com a opinião pública. Revista Rumores, n. 10, p. 1-17, jul./dez. 2011.

HERSCOVITZ, H. G. Análise de conteúdo em jornalismo. In: LAGO, C.; BENETTI, M. (Org.). Metodologia de pesquisa em jornalismo. 2. ed. Petrópolis, RJ: Vozes, 2008.

JAKOBSEN, K. A cobertura da imprensa aos candidatos nas eleições presidenciais de 2006. In: LIMA, V. A. (Org.). A mídia nas eleições de 2006. São Paulo: Fundação Perseu Abramo, 2007. 
JOHNSON, T. S. P. Entre hard e soft news: explorando modelos de personalização de notícias em plataformas sociais. Lumina - Revista do Programa de Pós-Graduação em Comunicação da Universidade Federal de Juiz de Fora, Juiz de Fora, v. 9, n. 2, 2015.

KARAM, F. J. C. A ética e o interesse público. São Paulo: Summus, 2004.

LAGE, N. Conceitos de jornalismo e papéis sociais atribuídos aos jornalistas. Pauta Geral Estudos em Jornalismo, v. 1, n. 1, 2014. Disponível em: <http://www.revistas2.uepg.br/index.php/pauta/article/view/6080>. Acesso em: 3 abr. 2017.

LIPPMANN, W. Opinião Pública. 2. ed. Petrópolis, RJ: Vozes, 2010.

MACHADO, M. B.; MOREIRA, F. Jornalismo e informação de interesse público. Revista Famecos, Porto Alegre, n. 27, 2005.

MARQUES, F. P. J. A. Cidadão, eleitor e usuário: observações acerca das campanhas eleitorais digitais. Em Debate, Belo Horizonte, v. 4, n. 7, p. 7-15, out. 2012.

MASSUCHIN, M. G.; CARVALHO, F. C. Conteúdo jornalístico nas redes sociais: as estratégias dos jornais brasileiros no facebook. Textual \& Visual Media, n. 9, p. 155-176, 2016.

MCCOMBS, M. A Teoria da Agenda: a mídia e a opinião pública. Petrópolis, RJ: Vozes, 2009.

MIGUEL, L. F. Quanto vale uma valência? Revista Brasileira de Ciência Política, n. 17, Brasília, maio/ago. 2015.

PITOMBO, J. P. Jornal 'A Tarde', da Bahia, é vendido para empresa paulista. Folha de São Paulo, São Paulo, 28 jan. 2016. Disponível em: $<$ http://www1.folha.uol.com.br/mercado/2016/01/1734706-jornal-a-tarde-da-bahia-e-vendidopara-empresa-paulista.shtml>. Acesso em: 9 abr. 2017.

SILVA, B. F. da; PELliZZARO, A. C. A cobertura da eleição presidencial de 2014 no Facebook: aspectos da visibilidade da campanha e dos candidatos nas postagens do Estadão, Folha de S. Paulo e O Globo. In: SEMINÁRIO NACIONAL DE SOCIOLOGIA E POLÍTICA: RELEITURAS CONTEMPORÂNEAS: O BRASIL NA PERSPECTIVA DAS CIÊNCIAS SOCIAIS, 6, 2015, Curitiba. Anais... Disponível em: <http://www.edemocracia.com.br/sociologia/anais_2015/busca-por-area/>. Acesso em: 30 jun. 2016.

SOUSA, P. J. Construindo uma teoria multifactorial da notícia como uma Teoria do Jornalismo. Estudos em Jornalismo e Mídia, Florianópolis, v. 2, n. 1, 1. sem. 2005. Disponível em: <https://periodicos.ufsc.br/index.php/jornalismo/article/view/2090>. Acesso em: 3 abr. 2017.

TAVARES, C. Q.; MASSUCHIN, M. G. Campanha eleitoral nas redes sociais: um estudo sobre as estratégias empregadas pelos candidatos à Presidência da no Facebook em 2014. Trabalho apresentado no 4. Fórum Brasileiro de Pós-Graduação em Ciência Política, Niterói, 2015. 
BORGES, R. F. Redes sociais, jornalismo e eleições locais em 2016: o Facebook como espaço de visibilidade da politica e dos políticos nos jornais O Estado do Maranhão (MA) e A Tarde (BA)

TRAQUINA, N. Teorias do Jornalismo: porque as notícias são como são. 2. ed. Florianópolis: Insular, 2005.

TRIBUNAL SUPERIOR ELEITORAL. Conheça as novas regras das Eleições Municipais de 2016. Disponível em: <http://www.tse.jus.br/imprensa/noticias-tse/2016/Janeiro/conheca-asnovas-regras-das-eleicoes-municipais-de-2016>. Acesso em: 22 de junho de 2017.

WEBER, M. H.; COELHO, M. P. Entre jornalismo e poderes. In: SILVA, G. et al. (Org.). Jornalismo contemporâneo: figurações, impasses e perspectivas. Salvador: EDUFBA; Brasília: Compós, 2001.

ZAGO, G. da S.; BASTOS, M. T. Visibilidade de notícias no Twitter e no Facebook. Revista Jounarlism Research, v. 9, n. 1, 2013. 